\title{
Investigating the Causes of Elderly People Leaving Home during Coronavirus Disease-19 Epidemic
}

\author{
Morad Ali Zareipour ${ }^{1}$, Ali Sadaghianifar ${ }^{1}$, Najaf Ahmadi Aghziyarat ${ }^{1}$, Mina Tasouji Azari ${ }^{2}$, Monireh Rezaee Moradali ${ }^{3 *}$ \\ ${ }^{1}$ Health System Research Unit, Health Center of Urmia, Urmia University of Medical Sciences, Urmia, Iran; ${ }^{2}$ Department of \\ English Language, Islamic Azad University, Tabriz, Iran; ${ }^{3}$ Student Research Committee, Midwifery and Reproductive Health \\ Research Center, School of Nursing and Midwifery, Shahid Beheshti University of Medical Sciences, Tehran, Iran
}

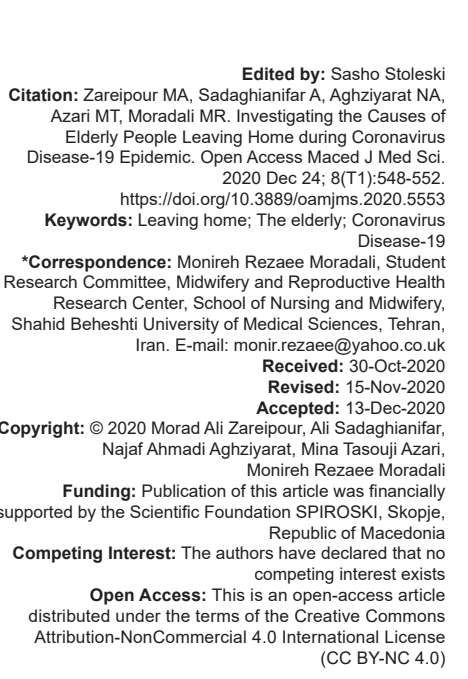

Abstract

BACKGROUND: Coronavirus disease-19 (COVID-19) disease affects all age groups, especially the elderly, and regarding the high mortality rate among the elderly, preventive measures are needed to reduce mortality in the elderly.

AIM: This study was conducted to investigate the causes of in elderly people leaving home in time of COVID-19 epidemic.

METHODS: The present study is a descriptive-analytical study performed on 1656 elderly people in Urmia, Iran by simple random sampling method. The data collection tool in this study was a researcher-made questionnaire that included demographic characteristics, a questionnaire on the causes of the elderly leaving home during the COVID-19 epidemic. Data were analyzed using Chi-square and Fisher tests using SPSS 23 software.

RESULTS: The results revealed that the highest concern of the elderly to leave home was to receive health services $(45.89 \%)$ such as visiting the doctor or the caregiver, receiving medication, and so on. As the second priority, buying daily necessities such as bread, food, clothes ... (42.75\%) was one of the reasons for the elderly to leave home. Furthermore, education, gender, age, underlying diseases, occupation, and living conditions of the elderly were related to the needs of health services and living necessities and this relationship was statistically significant $(\mathrm{p}<0.05)$

CONCLUSION: Effective interventions should be designed based on the causes of the elderly leaving home including the use of home distance care and health ambassadors to estimate the needs and causes of leaving home. Therefore, the elderly would be protected from this disease and its mortality.

\section{Introduction}

The World Health Organization (WHO) claimed coronavirus disease-19 (COVID-19) disease as an epidemic, and a new, different one from other viruses of severe acute respiratory syndrome, Middle East respiratory syndrome, and influenza [1]. The morbidity rate and mortality rate of the COVID-19 are growing and the economic damage resulting from the disease is highly increasing, estimated to overpass the capacity of both developed and developing countries in forthcoming months [2]. Elderly people are one of the high-risk groups with a high possibility of morbidity and mortality, due to old age as well as high statistics of underlying diseases. Therefore, elderly people are at higher risk of catching the disease and death from the COVID-19 more than other groups of society [3]. Studies on the elderly showed that they not only face a higher risk of catching the disease but also are at a greater risk of death of the disease. However, the reason of the fact that old people with underlying diseases are at higher risk of the disease is unknown [4]. The results of a study in China showed that $92 \%$ of the people affected by COVID-19 were elderly over 72 , while more than $42 \%$ of the death from COVID-19 were of them. It is also reported to have $82 \%$ of the deaths from COVID-19 among elderly over 60 in the U.S [5], [6]. Old people are more susceptible of the disease because underlying diseases such as renal failure, diabetes, high blood pressure, arthritis, heart diseases, and chronic obstructive pulmonary disease are more common among the elderly. Recent research revealed that the high rate of morbidity among the elderly is due to diagnostic disorders, immune system deficiency, underlying diseases, malnutrition, taking multiple drugs, and social problems. Thus, in developing countries, the number of elderly people affected from and died of COVID-19 outnumbers other age groups [7]. Weak preventive measurements among the elderly indicate they have not taken the significance of the issue seriously and have not considered COVID-19 as a threat to their health. To diagnose the preventive measurements and to control the spread of the COVID-19, the determinants and contributory factors on preventive behavior from the disease should have been identified [4]. 
Regarding the ways of transmission for this disease, home quarantine is one of the main influential ways in removing the transmission cycle of the disease [8]. Staying at home and not commuting out would reduce the elderlies' contact with each other, as well as the environment, therefore, decreases the transmission of the disease from one person to the other or to the environment [9].

Findings of the studies conducted by Daoust in 27 countries were dramatically clear and alarming: Despite the fact that the probability of death from COVID-19 is much higher among the elderly, they seldom regard preventive measures like staying at home [10]. Therefore, the behavior of the elderly in preventing the disease and staying home is crucial toward advancing home-quarantine policies. However, the needs of the elderly should be noticed for their home quarantine. The elderly people often have complicated and unknown needs, and besides their physical disorders, they have psychological, social, environmental, protective, and health-relevant problems [11]. Daily needs of the elderly are of important factors in preventing COVID-19, for their leaving home. Therefore, it is of vital importance to identify the daily needs of the elderly and providing them to prevent their home-leaving. The purpose of the present study is to identify the reasons of the elderly people home leaving during the coronavirus epidemic in Urmia, Iran.

\section{Materials and Methods}

The present study is a descriptive-analytical one, aiming at investigating the reasons of the elderly people home-leaving in time of coronavirus epidemic in 1399 (2020), conducted in Urmia, Iran. Regarding the population of the elderly in Urmia (51000), of which, $3.25 \%$ was chosen as the sample to study, and 1656 persons were included in the study. Using simple random sampling from 30 health centers of Urmia, $3.25 \%$ of the elderly people were selected in the proportion of the population of each health center. Data collection instruments of the present research study were researcher-made, including the demographic specifications of the participants and the Elderly HomeLeaving Questionnaire. The items of the determined consequences were selected through the literature review, and to meet the reliability and validity of the questionnaire, the methods of content validity and Cronbach-alpha were implemented respectively. To indicate the reliability of the questionnaire, it was sent to 10 experts in health education and elderly science, and the comments were applied according to their opinions. The reliability of the questionnaire was more than $80 \%$. To measure the validity, the questionnaire was completed by 30 elderly people who were not included in the group under study. Using the Cronbachalpha method, reliability coefficient of the health and therapeutic questions $0 / 77$; referring to the banks and offices 0/78; living necessities 0/28; social and recreational interactions $0 / 80$; and being in ceremonies and occasions 0/83 were reported.

To assess the above-mentioned dimensions in 24 questions which were provided as Yes/No choices and the Yes ones were pointed as 1, while the No answers were pointed as 0 . The points were varied from 0 to 24; as the health-therapeutic dimension had 4 questions, referring to the banks and offices 6 questions, living necessities 5 questions, social and recreational interactions 4 questions, and being in ceremonies and occasions 5 questions.

Health-care providers communicated with the elderly through phone calls and the purpose of the study was elaborated to all the participants. Then, the questionnaire was completed through phone interviews by elderly people. In addition, the time range of the home-leaving was considered as 1 week before. The criteria for taking part in the study were age over 60 , capability of answering through phone, not abiding in nursery home, while the items of not satisfaction, not being inclined to contribute in the research were excluded from the study. The descriptive data were analyzed in terms of frequency (in percent), and analytical data through Chi-square and Fisher tests using SPSS 23 software.

\section{Results}

The average age of the elderly people participated in the study was $66 / 4 \pm 8 / 87$, while the biggest age group was 60-65 (33\%). Most of the elderly were women $(51 / 1 \%)$, being housewives (49/2\%). The living conditions indicated that most of the elderly people under study live with their spouses (79/7\%). Moreover, most elderly people were illiterate (45/7\%), and $72 / 5 \%$ of them were suffering from a chronic disease (cardiovascular, respiratory, diabetes, blood pressure, etc. diseases) Table 1.

The findings of the reasons of elderly homeliving indicated that their biggest concern of going out of home was to receive health-therapeutic service like visiting the doctor or the caregiver, and medication $(45 / 89 \%)$. The second priority of the elderly homeleaving reason was to buy daily necessities such as bread, food supplies, clothing, and so on (42/75\%). Besides, 21/02 percent of the elderly people leave home to pay their electricity, gas, and phone bills, as well as to get their payrolls. Taking part in social and recreational interactions was of weak reasons of their home-leaving of the elderly (Table 2). 
Table 1: Frequency and the distribution percentage of the demographic features of the elderly under study

\begin{tabular}{lll}
\hline Variables & Number & Percent \\
\hline Age & & \\
$60-65$ & 547 & 33 \\
$65-70$ & 497 & 30 \\
$70-75$ & 414 & 25 \\
$80-75$ & 198 & 12 \\
Sex & & \\
$\quad$ Male & 809 & 48.9 \\
Female & 847 & 51.1 \\
Job & & \\
Housewife & 815 & 49.2 \\
Employed & 278 & 16.8 \\
Retired & 563 & 34 \\
Living condition & & \\
With spouses & 1320 & 79.7 \\
Alone & 112 & 6.8 \\
$\quad$ With children & 224 & 13.5 \\
Education & & \\
$\quad$ Illiterate & 757 & 45.7 \\
Elementary & 577 & 34.8 \\
Diploma and postgraduate & 211 & 12.7 \\
& 111 & 6.7 \\
History of chronic diseases & & 72.5 \\
Yes & 1201 & 27.5 \\
$\quad$ No & 455 & \\
\hline
\end{tabular}

The results of Chi-square and Fisher test revealed that home-leaving of elderly to receive healththerapeutic services, going to the banks and offices, buying living necessities, and social-recreational interactions were more among elderly people with higher education. Moreover, elderly women had homeleaving to receive health and therapeutic services more than men. In contrast, elderly men leave home to go to banks and offices, to buy living necessities, and social, recreational interactions more than women with a

Table 2: The frequency and the distribution percentage of the home-leaving elderly under study

\begin{tabular}{llllll}
\cline { 1 - 2 } Variables of the elderly home-leaving & Yes & & No & \\
\cline { 2 - 3 } \cline { 5 - 6 } & Frequency & Percent & Frequency & Percent \\
\hline Social/recreational interactions & 823 & $12 / 42$ & 5801 & $87 / 58$ \\
Going to parks & 131 & $7 / 91$ & 1525 & $92 / 09$ \\
Being in streets, sectors & 371 & $22 / 40$ & 1285 & $77 / 60$ \\
Visiting relatives and friends & 196 & $11 / 84$ & 1460 & $88 / 16$ \\
In/out city communities & 125 & $7 / 55$ & 1531 & $92 / 45$ \\
Being in ceremonies and occasions & 195 & $2 / 36$ & 8085 & $97 / 64$ \\
Visiting the patients & 53 & $3 / 20$ & 1603 & $96 / 80$ \\
The obit, funeral & 74 & $4 / 47$ & 1582 & $95 / 53$ \\
The birthday parties & 14 & $0 / 85$ & 1642 & $99 / 15$ \\
The wedding parties & 28 & $1 / 69$ & 1628 & $98 / 31$ \\
The religious ceremonies & 26 & $1 / 57$ & 1630 & $98 / 43$ \\
Referring to the offices and banks & 2089 & $21 / 02$ & 7847 & $78 / 98$ \\
To unbound and free Edalat stocks & 198 & $11 / 96$ & 1458 & $88 / 04$ \\
To pay bank installment & 318 & $19 / 20$ & 1338 & $80 / 80$ \\
To pay bills of gas, electricity, & 365 & $22 / 04$ & 1291 & $77 / 96$ \\
To get money from ATM & 550 & $33 / 21$ & 1106 & $66 / 79$ \\
To receive payrolls & 234 & $14 / 13$ & 1422 & $85 / 87$ \\
To receive subsidy and livelihood & 424 & $25 / 60$ & 1232 & $74 / 40$ \\
Health-therapeutic issues & 3040 & $45 / 89$ & 3584 & $54 / 11$ \\
Doing tests and risk assessments & 632 & $38 / 16$ & 1024 & $61 / 84$ \\
Receiving Medications & 737 & $44 / 50$ & 919 & $55 / 50$ \\
Doctor visiting & 949 & $57 / 31$ & 707 & $42 / 69$ \\
Referring to the caregivers & 722 & $43 / 60$ & 934 & $56 / 40$ \\
To buy living necessities & 3540 & $42 / 75$ & 4740 & $57 / 25$ \\
Buying clothing & 532 & $32 / 13$ & 1124 & $67 / 87$ \\
Buying sanitary fittings (shampoo, soap) & 756 & $45 / 65$ & 900 & $54 / 35$ \\
Buying home appliances & 450 & $27 / 17$ & 1206 & $72 / 83$ \\
Buying food & 902 & $54 / 47$ & 754 & $45 / 53$ \\
Buying bread & 900 & $54 / 35$ & 756 & $45 / 65$ \\
\hline & & & & \\
\hline
\end{tabular}

significant meaning statistically $(p<0 / 05)$. On the other hand, older people leave home mostly to receive healththerapeutic services, while elderly with lower age heave home to buy living necessities, and this difference was more meaningful among age groups home-leaving $(p<0 / 05)$. The findings of investigating the relationship between underlying diseases and the reasons of elderly home-leaving revealed that the elderly people with underlying diseases refer more to the health centers, while leave homeless for providing living necessities and official or bank affairs. Employed elderly leave home more than other groups in all dimensions but attending the ceremonies and occasions. Living alone was the other reason of the elderly home leaving. All above-mentioned reasons were significant statistically $(p<0 / 05)$ Table 3.

\section{Discussion}

Since no study has been conducted on the issue so far, the viewpoints, approaches, and suggestions were most discussed in this study. The results showed that the biggest mental concern of the elderly leaving home is health and therapeutic issues. It seems that elderly people with more physical problems refer to health centers for treatment. In studies conducted in Iran [12], Turkey [13], and Uganda [14], the reported level of health for the elderly was weak. The reason can be related to the increasing frequency of the various concurrent diseases in the elderly. On the other hand, the assessment of the relationship between demographic variables with the elderly home leaving to provide sanitary fittings was meaningful. According to the report of $\mathrm{WHO}$, the elderly were at higher risk of getting the coronavirus [15]. Since the mortality rate is high among old people, it is suggested in to reduce the elderly commuting and encountering the virus, medical care be done through tele home care (THC), so better management of the elderly with underlying diseases such as cardiovascular diseases, COPT, diabetes, and so on resulted elderly people less home leaving to receive health care services. THC increases the access to health and sanitary services, particularly when the importance of the need of the elderly for in-home care increases. Moreover, THC can help establish the service network between hospitals and first-aid providers, through which will facilitate the opportunity of better accessibility of the elderly to the services. In addition to the improvement of the management of the chronic condition as well as the increasing availability of health care, THC believes that it would decrease the health care expenses as well [16], [17]. Eventually, it should be noted in $\mathrm{THC}$, the prioritizing $\mathrm{THC}$, implemented according to the meaningful relationship of the demographic variables with health and sanitary needs. For instance, women and lonely elderly people who leave home more than other groups to receive health and therapeutic services should be prioritized.

Other findings of the present study indicated the amplitude of daily needs (buying bread, food, sanitary fittings, etc.), as well as referring to the banks and offices, as the reasons of home leaving. Daily necessities are mentioned as part of major environmental needs of 
Table 3: Investigating the relationship between demographic variables with the home-leaving of the elderly

\begin{tabular}{|c|c|c|c|c|c|c|c|c|c|c|}
\hline \multirow[t]{2}{*}{ Demographic variables } & \multicolumn{2}{|c|}{ Health issues (\%) } & \multicolumn{2}{|c|}{$\begin{array}{l}\text { Going to banks and } \\
\text { offices }(\%)\end{array}$} & \multicolumn{2}{|c|}{$\begin{array}{l}\text { Buying living } \\
\text { necessities (\%) }\end{array}$} & \multicolumn{2}{|c|}{$\begin{array}{l}\text { Social and recreational } \\
\text { interactions }(\%)\end{array}$} & \multicolumn{2}{|c|}{$\begin{array}{l}\text { Going to ceremonies and } \\
\text { occasions (\%) }\end{array}$} \\
\hline & Yes & No & Yes & No & Yes & No & Yes & No & Yes & No \\
\hline \multicolumn{11}{|l|}{ Education } \\
\hline Illiterate & $1320(43 / 6)$ & $1708(56 / 4)$ & $621(13 / 7)$ & $3921(86 / 3)$ & $1167(30 / 8)$ & $2618(69 / 2)$ & $353(11 / 7)$ & $2675(88 / 3)$ & $80(2 / 1)$ & $3705(97 / 9)$ \\
\hline High school & $1089(47 / 2)$ & $1219(52 / 8)$ & $903(26 / 1)$ & 2559 (73/9) & $1474(51 / 1)$ & $1411(48 / 9)$ & $319(13 / 8)$ & $1989(86 / 2)$ & $81(2 / 8)$ & $2804(97 / 2)$ \\
\hline Diploma & $433(51 / 3)$ & $411(48 / 7)$ & $388(30 / 6)$ & $878(69 / 4)$ & $575(54 / 5)$ & $480(45 / 5)$ & $87(10 / 3)$ & $757(89 / 7)$ & $18(1 / 7)$ & $1037(98 / 3)$ \\
\hline Academic studies & $198(44 / 6)$ & $246(55 / 4)$ & $177(26 / 6)$ & $489(73 / 4)$ & $324(58 / 4)$ & $231(41 / 6)$ & $64(14 / 4)$ & $380(85 / 6)$ & $16(2 / 9)$ & $539(97 / 1)$ \\
\hline$p$ value & $0 / 000$ & & $0 / 000$ & & $0 / 000$ & & $0 / 012$ & & $0 / 105$ & \\
\hline \multicolumn{11}{|l|}{ Gender } \\
\hline Male & $1419(43 / 9)$ & $1817(56 / 1)$ & $1529(31 / 5)$ & $3325(68 / 5)$ & $2318(57 / 3)$ & $1727(42 / 7)$ & $468(14 / 5)$ & $2768(85 / 5)$ & $92(2 / 3)$ & $3953(97 / 7)$ \\
\hline Female & $1621(47 / 8)$ & $1767(52 / 2)$ & $560(11)$ & $4522(89)$ & $1222(28 / 9)$ & $3013(71 / 1)$ & $355(10 / 5)$ & $3033(89 / 5)$ & $103(2 / 4)$ & $4132(97 / 6)$ \\
\hline$p$ value & $0 / 001$ & & $0 / 000$ & & $0 / 000$ & & $0 / 000$ & & $0 / 636$ & \\
\hline \multicolumn{11}{|l|}{ Age groups } \\
\hline $60-65$ & $1618(44)$ & $2058(56)$ & $1171(21 / 2)$ & $4343(78 / 8)$ & 2070 (45) & 2525 (55) & $463(12 / 6)$ & $3213(87 / 4)$ & $116(2 / 5)$ & $4479(97 / 5)$ \\
\hline $65-70$ & $251(40 / 5)$ & $369(59 / 5)$ & $472(20 / 9)$ & $1784(79 / 1)$ & $448(43 / 5)$ & $582(56 / 5)$ & $168(11 / 2)$ & $1336(88 / 8)$ & $36(1 / 9)$ & $1844(98 / 1)$ \\
\hline $70-75$ & $424(51 / 5)$ & $400(48 / 5)$ & $271(21 / 9)$ & $965(78 / 1)$ & $778(41 / 4)$ & $1102(58 / 6)$ & $117(14 / 2)$ & $707(85 / 8)$ & $30(2 / 9)$ & $1000(97 / 1)$ \\
\hline$>75$ & $747(49 / 7)$ & $757(50 / 3)$ & $175(18 / 8)$ & $755(81 / 2)$ & $244(31 / 5)$ & $531(68 / 5)$ & $75(12 / 1)$ & $545(87 / 9)$ & $13(1 / 7)$ & $762(98 / 3)$ \\
\hline$p$ value & $0 / 000$ & & $0 / 321$ & & $0 / 000$ & & $0 / 194$ & & $0 / 165$ & \\
\hline \multicolumn{11}{|l|}{ Underlying diseases } \\
\hline Have & $2491(51 / 7)$ & $2325(48 / 3)$ & $1432(19 / 8)$ & $5792(80 / 2)$ & $2406(40)$ & $3614(60)$ & $600(12 / 5)$ & $4216(87 / 5)$ & $148(2 / 5)$ & $5872(97 / 5)$ \\
\hline Not have & $549(30 / 4)$ & $1259(69 / 6)$ & $657(24 / 2)$ & $2055(75 / 8)$ & $1134(50 / 2)$ & $1126(49 / 8)$ & $223(12 / 3)$ & $1585(87 / 7)$ & $47(2 / 1)$ & $2213(97 / 9)$ \\
\hline$p$ value & $0 / 000$ & & $0 / 000$ & & $0 / 000$ & & $0 / 891$ & & $0 / 311$ & \\
\hline \multicolumn{11}{|l|}{ Job } \\
\hline Retired & $285(12 / 7)$ & $1967(87 / 3)$ & $1053(31 / 2)$ & $2325(68 / 8)$ & $1503(53 / 4)$ & $1312(46 / 6)$ & $285(12 / 7)$ & $1967(87 / 3)$ & $59(2 / 1)$ & $2756(97 / 9)$ \\
\hline Housewives & $348(10 / 7)$ & $2912(89 / 3)$ & $478(9 / 8)$ & $4412(90 / 2)$ & $1121(27 / 5)$ & $2954(72 / 5)$ & $348(10 / 7)$ & $2912(89 / 3)$ & $96(2 / 4)$ & $3979(97 / 6)$ \\
\hline Employed & $190(17 / 1)$ & $922(82 / 9)$ & $558(33 / 5)$ & $1110(66 / 5)$ & $916(65 / 9)$ & $474(34 / 1)$ & $190(17 / 1)$ & $922(82 / 9)$ & $40(2 / 9)$ & $1350(97 / 1)$ \\
\hline$p$ value & $0 / 027$ & & $0 / 000$ & & $0 / 000$ & & $0 / 000$ & & $0 / 290$ & \\
\hline \multicolumn{11}{|l|}{ Living condition } \\
\hline With spouses & $2345(44 / 4)$ & $2935(55 / 6)$ & $212(15 / 8)$ & $1132(84 / 2)$ & 347 (31) & $773(69)$ & $122(13 / 6)$ & $774(86 / 4)$ & $34(3)$ & $1086(97)$ \\
\hline Alone & $471(52 / 6)$ & $425(47 / 4)$ & $1741(22)$ & $6179(78)$ & $267(47 / 7)$ & $293(52 / 3)$ & $651(12 / 3)$ & $4629(87 / 7)$ & $148(2 / 2)$ & $6452(97 / 8)$ \\
\hline With children & $224(50)$ & $224(50)$ & $136(20 / 2)$ & $536(79 / 8)$ & $2926(44 / 3)$ & $3674(55 / 7)$ & $50(11 / 2)$ & $398(88 / 8)$ & $13(2 / 3)$ & $547(97 / 7)$ \\
\hline$p$ value & $0 / 000$ & & $0 / 000$ & & $0 / 000$ & & 0/395 & & $0 / 266$ & \\
\hline
\end{tabular}

the elderly in other various studies, and speculated their environmental need different according to their residence [18], [19], [20]. Due to the fact that it is inevitable for the elderly to provide daily needs and to refer to the banks, the elderly have to leave home to provide them. In this regard, the family and relatives should help the elderly, do the out of home activities for them. Educating families so that one of the close people to the elderly takes the responsibility of providing his/her necessities is an important issue, of which media play an important role in this regard. Therefore, it is suggested to implement Health Ambassadors to provide the elderly necessities and to pay their bills. The ministry of health has initiated training Family Health Ambassadors since 1393 (2014), who is a young member of the family with at least 8 years of school studies, taking responsibility of conveying health-related learned issues, as well as active care of himself, his family members, and society voluntarily. Volunteer Health Ambassador is trained for every family without any competent member [21], [22]. The Family Health Ambassador can act as a link between health system and the families under coverage, to receive the sanitary data about coronavirus in person or electronically, and convey them to the families to provide self-care. Of other activities supposed for family, health ambassador is buying daily necessities of the elderly and paying their bills. Consequently, the elderly would not have to leave home and the young, informed person of the ways and possibilities of transmission of the coronavirus would do them instead. For families without such a person, a volunteer health ambassador from other families would be employed to do this. It is worthy of noting that demographic features such as age, gender, and education are related to the frequency of home leaving to provide daily needs and to pay the bills, thus should be taken into account in administrating the provision of the daily needs of the elderly by the health ambassadors.

Fortunately, having social and recreational interactions was one of the weak reasons of the elderly going out. However, most of the affected and hospitalized patients in corona wards usually attended in family gatherings, wedding and funeral ceremonies, as well as gathering places 2 weeks before getting the disease. Thus, it is of vital importance to educate and sensitize the elderly in terms of not attending in ceremonies and highly crowded places such as parks, streets, as well as visiting and traveling. It should be prioritized, particularly for the men and employed elderly who have a higher frequency of home leaving to meet their social and recreational needs.

\section{Conclusion}

Regarding the findings of the present study, it is suggested to design precise planning for the elderly people on the basis of their home leaving reasons, like using THC, and Health Ambassadors, which are influential in estimating the home leaving reasons and preventing the elderly from getting the disease and associated death.

\section{References}

1. World Health Organization. WHO Director General's Opening Remarks at the Media Briefing on COVID-19. Geneva: World 
Health Organization; 2020.

2. Zareipour MA. The role of social participation in controlling and preventing of coronavirus 2019 disease in Iran. Open Access Maced J Med Sci 2020;8:1-3. https://doi.org/10.3889/ oamjms.2020.4956

3. Wang L, He W, Yu X, Hu D, Bao M, Liu H, et al. Coronavirus disease 2019 in elderly patients: Characteristics and prognostic factors based on 4-week follow-up. J Infect. 2020;80(6):639-45. https://doi.org/10.1016/j.jinf.2020.03.019

PMid:32240670

4. Xiang YT, Yang Y, Li W, Zhang L, Zhang Q, Cheung T, et al. Timely mental health care for the 2019 novel coronavirus outbreak is urgently needed. Lancet Psychiatry 2020;7(3):2289. https://doi.org/10.1016/s2215-0366(20)30046-8 PMid:32032543

5. Chen J, Wang L, Huang R, Chen J. Home care for the elderly under the epidemic of novel coronavirus pneumonia. Am J Nurs. 2020;9(3):145-8. https://doi.org/10.11648/j.ajns.20200903.22

6. Benksim A, Rachid A, Cherkaoui M. Vulnerability and fragility expose older adults to the potential dangers of COVID-19 pandemic. Iran J Public Health. 2020;49(1):122-4. https://doi. org/10.18502/ijph.v49is1.3682

7. Kline KA, Bowdish DM. Infection in an aging population. Curr Opin Microbiol. 2016;29:63-7. https://doi.org/10.1016/j. mib.2015.11.003

PMid:26673958

8. Wang J, Liao Y, Wang X, Li Y, Jiang D, He J, et al. Incidence of novel coronavirus (2019-nCoV) infection among people under home quarantine in Shenzhen, China. Travel Med Infect Dis. 2020;2020:101660. https://doi.org/10.1016/j. tmaid.2020.101660

9. Santesmasses D, Castro JP, Zenin AA, Shindyapina AV, Gerashchenko MV, Zhang B, et al. COVID-19 is an emergent disease of aging. MedRxiv. 2020;19(10):1-10. https://doi. org/10.1111/acel.13230

10. Daoust JF. Elderly people and responses to COVID-19 in 27 countries. PLoS One. 2020;15(7):e0235590. https://doi. org/10.1371/journal.pone.0235590 PMid:32614889

11. Passos J, Sequeira C, Fernandes L. The needs of older people with mental health problems: A particular focus on dementia patients and their carers. Int J Alzheimers Dis. 2012;2012:638267. https://doi.org/10.1155/2012/638267 PMid:23193496

12. Ghasemi S, Mohammadi N, Shahboulaghi F, Ramezankhani A, Mehrabi Y. Physical health status of the elderly living at home in Tehran city, Iran. Sci Inform Database. 2019;13(1):652-62. https://doi.org/10.32598/sija.13.special-issue.652

13. Deandrea S, Lucenteforte E, Bravi F, Foschi R, La Vecchia C, Negri E. Risk factors for falls in community-dwelling older people: A systematic review and meta-analysis. Epidemiology. 2010;21(5):658-68. https://doi.org/10.1097/ ede.0b013e3181e89905

PMid:20585256

14. Wandera SO, Golaz V, Kwagala B, Ntozi J. Factors associated with self-reported ill health among older Ugandans: A cross sectional study. Arch Gerontol Geriatr. 2015;61(2):231-9. https:// doi.org/10.1016/j.archger.2015.05.006 PMid:26043957

15. Available form: https://www.euro.who.int/en/health-topics/ Life-stages/healthy-ageing/data-and-statistics/health-careconsiderations-for-older-people-during-covid-19-pandemic. [Last accessed on 2020 Jun 12].

16. Koch $\mathrm{S}$. Home telehealth-current state and future trends. Int J Med Inform. 2006;75(8):565-76. https://doi.org/10.1016/j. ijmedinf.2005.09.002 PMid: 16298545

17. Lemelin A, Godbout A, Pare G, Bernard S. Improved glycemic control through the use of a telehomecare program in patients with diabetes treated with insulin. Diabetes Technol Ther. 2020;22(4):243-8. https://doi.org/10.1089/dia.2019.0324 PMid:31657625

18. Ashokkumar T, Chacko T, Munuswamy S. Health care and social needs of the elderly: Assessed by the tool Camberwell assessment of need for the elderly. Int J Trop Med. 2011;6(5):97-9.

19. van der Ploeg ES, Bax D, Boorsma M, Nijpels G, van Hout HP. A cross-sectional study to compare care needs of individuals with and without dementia in residential homes in the Netherlands. BMC Geriatr. 2013;13(1):51. https://doi. org/10.1186/1471-2318-13-51 PMid:23706150

20. Walters K, lliffe S, Tai SS, Orrell M. Assessing needs from patient, carer and professional perspectives: The Camberwell assessment of need for elderly people in primary care. Age Ageing. 2000;29(6):505-10. https://doi.org/10.1093/ ageing/29.6.505 PMid:11191242

21. Ministry of Health and Medical Education. Instructions Executive Education Programs and Health Promotion. Tehran: Ministry of Health and Medical Education; 2015.

22. Zareipour M, Jadgal MS, Movahed E. Health Ambassadors role in self-care during COVID-19 in Iran. J Milit Med. 2020;22(6):672-4. 